\title{
Individual and family labor market impacts of chronic diseases
}

\section{Chronic diseases worsen labor market outcomes, but firms' hiring and retention policies can reduce them}

Keywords: chronic health conditions, labor supply, earnings, caregivers

\section{ELEVATOR PITCH}

Chronic health conditions are a global concern and can impact labor market outcomes of those diagnosed and their caregivers. Since the global prevalence of many chronic health conditions is on the rise, it is important to know what firms can do to retain and hire workers who are impacted. Firms can improve hiring by addressing biases against potential employees with chronic health conditions. Furthermore, firms can retain impacted workers by offering workplace flexibility such as partial sick leave, work hour flexibility, and part-time work options.

\section{KEY FINDINGS}

Pros
$\oplus$ Firms often face less competition in hiring
productive workers with disabilities.
$\oplus$ Firms can benefit by considering why potential
employees have employment gaps.
$\oplus$ Firms that reduce workplace bullying can benefit
from reductions in sickness absenteeism among
women and job exits among men.
$\oplus$ Firms benefit more from partial sick leave
programs when work resumption starts within
26 weeks and the initial work capacity starts at a
sufficiently high level.
$\oplus$ Through flexible working hours and allowing them
to shift to part-time work, firms can retain parents
of children with a chronic health condition.

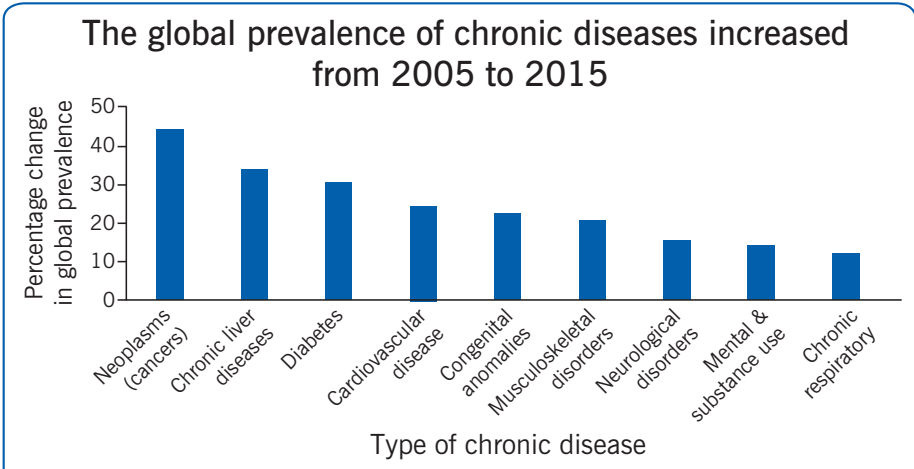

Source: Author's own compilation based on data in [1]. World of Labor

\section{Cons}

- Having a chronic health condition often leads to worse earnings and lower levels of employment.

- Mothers of children with a chronic health condition have worse labor market outcomes.

- A cancer diagnosis leads to lower income for both the person diagnosed and his/her spouse.

- Disability wage subsidies do not change firms' hiring decisions.

- Workplace wellness programs do not improve worker health, absenteeism, productivity, or retention.

\section{AUTHOR'S MAIN MESSAGE}

Those diagnosed with a chronic health condition and their caregivers often face reduced employment and lower earnings. Given the discrimination these workers can face, firms may have less competition in hiring talented workers with chronic health conditions. Moreover, firms that hire applicants with employment gaps can benefit by focusing on potential employees with resolved health issues. Finally, firms that care about worker retention should focus on workplace flexibility instead of workplace wellness programs. 


\section{MOTIVATION}

Chronic health conditions are a global health concern. The global prevalence of neoplasms (cancer), diabetes, asthma, anxiety disorders, and major depressive disorder as well as numerous other chronic health conditions is on the rise [1].

Those diagnosed with a chronic health condition and their caregivers often face reduced labor supply and lower earnings. However, firm policies can mitigate the impact. For example, firms could benefit from less competition in hiring talented workers by focusing on talented workers with disabilities and by considering that those with gaps in employment due to health shocks can be productive workers again after their recovery. Implementing partial sick leave, allowing caregivers to temporarily shift to part-time work, and allowing flexibility in working hours are complementary ways firms could retain impacted workers.

\section{DISCUSSION OF PROS AND CONS}

\section{Labor market impacts on the diagnosed individual}

Chronic health conditions could impact labor market outcomes for several reasons. Employers may not want to hire workers with chronic health conditions if they have higher levels of absenteeism, are less productive workers, or are going to increase health insurance costs for the firm. Managing a chronic health condition may interfere with skill upgrades and skill maintenance for those already in the labor force. Workers with certain chronic conditions may need to temporarily leave the workforce in order to receive necessary treatment.

Research using data from numerous countries generally finds that chronic health conditions lead to worse labor market outcomes. For example, a study using administrative data on Swedish males finds that the onset of a chronic health condition in adolescence is associated with lower earnings and lower employment in adulthood [2]. The authors compare outcomes for brothers with and without a chronic health condition, to hold family background constant. They find that a mental health condition is associated with a $6.4 \%$ decline in annual earnings and a 5 percentage point decline in employment. In contrast, there is a much smaller impact from asthma and hay fever and no significant impact from diabetes and migraines.

Research using the European Community Household Panel compares impacts across several European countries [3]. This study takes advantage of longitudinal data on health and labor market outcomes by comparing what the same person did before and after the onset of a chronic health condition. The control group comprised otherwise similar people who did not experience the onset of a chronic health condition. There are a few countries with no significant impact on employment (e.g. France, Belgium, and Italy), but in most countries the onset of a chronic health condition leads to worse employment (e.g. Ireland, Denmark, the Netherlands, Greece, Portugal, and Spain). Figure 1 shows that there is a lot of variation in labor market statuses after the onset of a chronic health condition across countries. The author of the study suggests that further analyses should be done to pinpoint the exact cause of this variation.

The impacts also vary across worker characteristics. A 2009 study finds that in the Australian National Health Surveys the employment effect from a chronic health condition is larger in magnitude for men than for women, because men originally had higher rates 
of labor force participation [4]. Health has a larger impact on the decision to leave employment for older workers, regardless of sex. Moreover, mental health conditions are shown to be especially harmful to employment, consistent with the previously mentioned Swedish study [2], [4]. The Australian study finds that older men are more negatively impacted by mental health conditions than younger men. Specifically, for older men, defined as those aged 50-64 years, the diagnosis of a mental health condition leads to a $25.6 \%$ decline in employment. For prime-aged men, defined as those aged 18-49 years, the diagnosis leads to a decline in employment of only $4.7 \%$.

Figure 1. The onset of a chronic disease has various impacts on labor outcomes

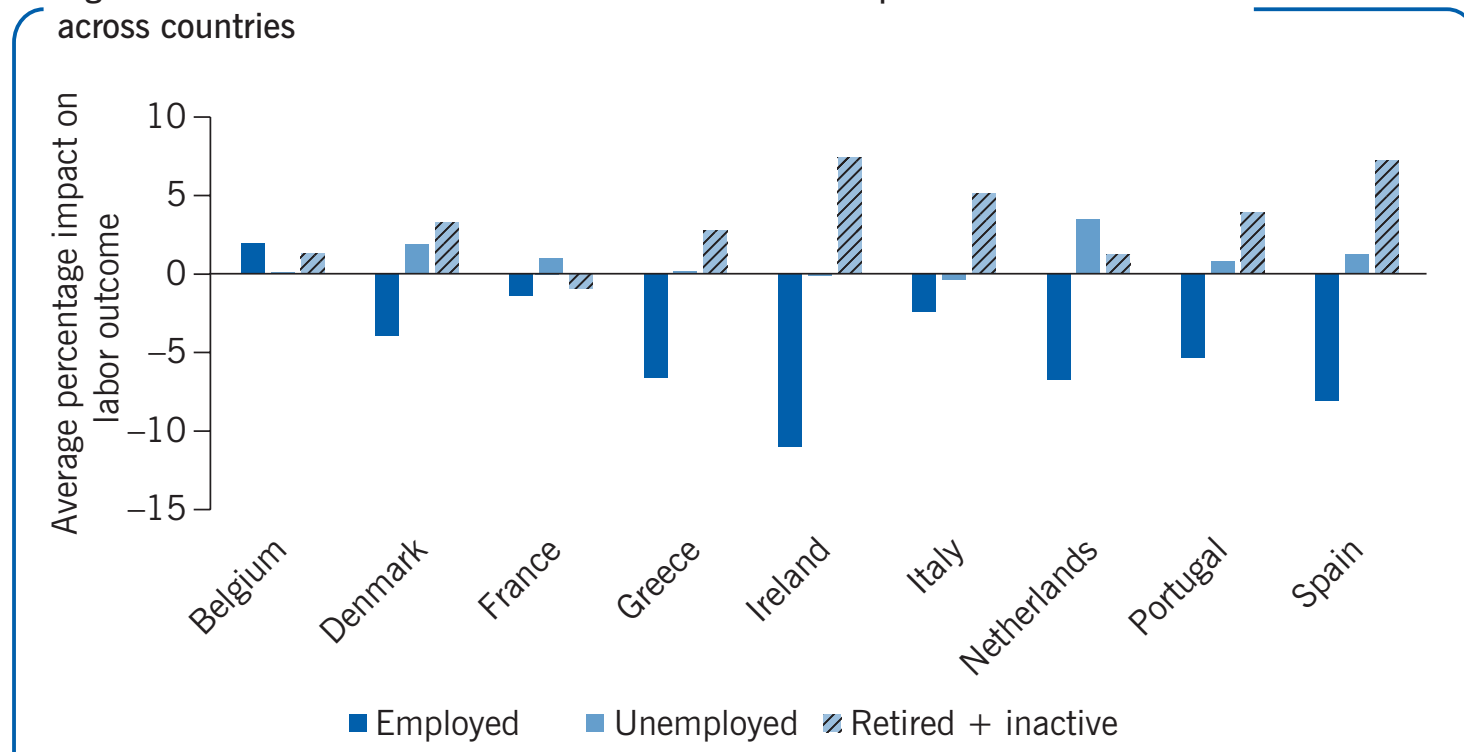

Source: Author's own compilation based on results in García-Goméz, P. "Institutions, health shocks and labour market outcomes across Europe." Journal of Health Economics 30:1 (2011): 200-213 [3].

The Australian study also reveals that workers often have multiple chronic health conditions [4]. The authors find that the impact on employment varies by how many chronic health conditions the worker has been diagnosed with. For example, for older males who have a chronic health condition diagnosed within the four major categories (cardiovascular diseases, diabetes, mental health problems, and "other chronic diseases") the labor force participation rate was only $27.8 \%$. In contrast, the labor force participation rate was $81.3 \%$ for older men without any chronic health condition. Thus, the Australian research suggests that in addition to considering whether someone has a chronic health condition, it is important to consider how many chronic health conditions they have [4].

\section{Impacts on parents}

Parents can also be impacted by a child's diagnosis. For example, parents may need to help children comply with treatment regimens, take them to medical appointments, order medicine, provide emotional support, and so on. Research finds that having a child with a chronic health condition or disability in Denmark leads to worse labor market outcomes, both when the disease does not qualify for government transfers [5] and when 
the type of disease does quality for government transfers [6]. In the research on nongovernment transfers, parents of children diagnosed with Type 1 diabetes are compared with similar families in which the child was not diagnosed [5]. Type 1 diabetes is an ideal candidate for causal research, given its characteristics. The research on government transfers focuses on chronic health conditions or disabilities that are diagnosed at birth or in early childhood and cannot be screened for during pregnancy, strengthening the argument that the diagnosis constitutes a health shock [6].

While both studies show negative impacts on parents, there are some important differences. With government transfers, mothers reduce their labor supply in terms of both leaving employment and reducing the hours they work [6], while in the absence of transfers mothers reduce their working hours but remain employed [5]. If the child is diagnosed before the age of six, the magnitude of the income reduction is larger for mothers in the context of no government transfers [5]. Both studies examine variation in effects across mother characteristics, but the scarcity of single mothers in Denmark makes it hard to estimate effects specific to that subgroup. In terms of paternal impacts, when government transfers are available there is a reduction in labor supply [6]; however, there are no long-term impacts when government transfers are not available [5]. The impacts are largest immediately following diagnosis when the condition does not qualify for government transfers [5]. In contrast, conditions that qualify for government transfers lead to larger impacts on maternal and paternal labor supply over time [6].

\section{Impacts on spousal labor supply}

Economic theory is unclear about whether spousal labor supply should increase or decrease after a health shock. If the spouse needs to help provide care, then a decrease in labor supply would be expected. On the other hand, if the health shock reduces the labor supply and earnings of the focal individual, spouses may need to increase their labor supply in order to make up for those lost earnings and help pay for care.

A study using administrative medical data and tax records from Canada finds that spousal labor supply is negatively impacted by a cancer diagnosis [7]. To estimate causal impacts the authors compare labor supply over time for those whose spouse received a cancer diagnosis with similar people whose spouse did not receive a cancer diagnosis. They show that earnings decreased by $3.5 \%$ for men whose spouse was diagnosed and by $6 \%$ for women whose spouse was diagnosed. While the percentage change was larger for women, the dollar amount of the decrease was smaller because women tend to earn less on average. The overall impact was a decline in family income of $4.8 \%$ for men and $8.5 \%$ for women. As shown in Figure 2, the effects on spousal earnings and family income were larger for cancers with lower survival probabilities. The same pattern also holds for spousal labor supply. Taken together, these results indicate that the severity of the chronic health condition also matters for caregivers' labor market outcomes.

\section{Hiring of talented workers impacted by chronic health conditions}

Given that workers diagnosed with a chronic health condition have lower levels of employment, it is important to understand why. A 2018 study focuses on determining 
Figure 2. More severe cancers lead to greater reductions in spousal earnings

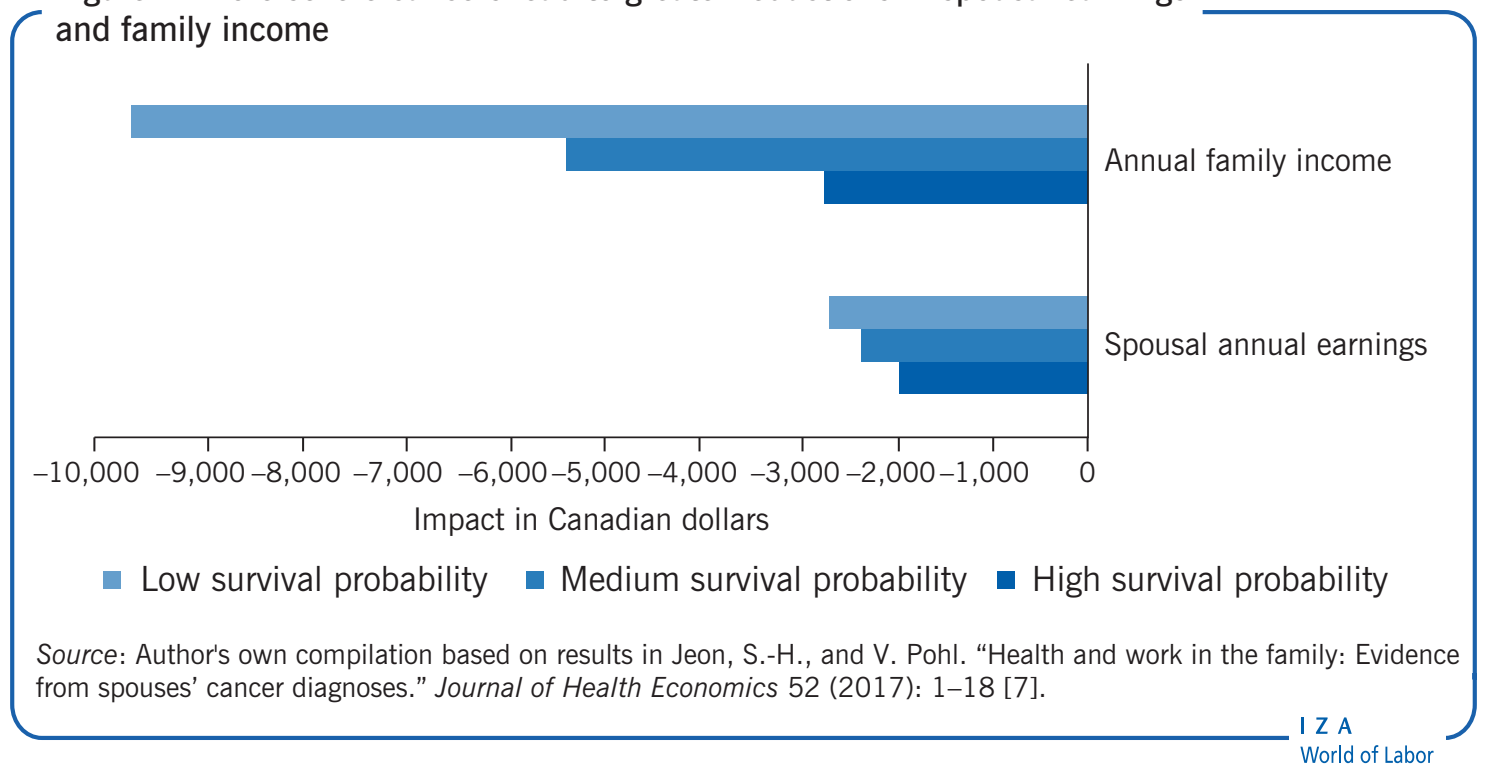

the importance of firm discrimination [8]. The authors move toward this explanation because the unemployment rate is twice as high for workers with a disability compared to those without a disability. They conducted an experiment in which three types of fictitious resumes were sent to accounting jobs: no disability disclosed, disclosure of a spinal cord injury, and disclosure of Asperger's syndrome. Spinal cord injuries and Asperger's syndrome were chosen because they should not signal the worker is less productive as an accountant.

The authors find that the applicants who disclosed a disability were $26 \%$ less likely to receive a callback. Additionally, there was little difference between the disabilities, despite evidence that people with Asperger's syndrome are often more productive in jobs like accounting. The effects were especially pronounced for jobs that require more experience. The authors note their findings are consistent with similar studies done in France and Belgium, indicating that the US is not a special case. These results are consistent with discrimination. Addressing this bias could be beneficial to firms because there is less competition in hiring qualified workers with disabilities compared to hiring qualified workers without disabilities.

Since firms may not want to hire workers with a disability, this raises the question of whether government policy can incentivize firms to change their behavior. The US hiring experiment also tested whether firms respond to the Americans with Disabilities Act and state laws related to disability discrimination in hiring practices [8]. While the federal law impacted firm behavior, the state laws had no impact. Thus, the results on penalizing firms are mixed.

However, an alternative strategy would be to reward firms for hiring disabled workers. Experimental research has been conducted on the Belgian wage subsidy [9]. The author uses three types of fictitious resumes for male applicants: no disclosed disability, disclosed disability (blind, deaf, or has autism), and disclosed disability plus approval for the wage subsidy if the worker is hired. The subsidy should not be a signal of the severity of the disability as being blind, deaf, or having autism all qualify once the person completes the paperwork. The authors find no statistical difference in the callback rates for those with 
a disclosed disability compared to those with a disclosed disability plus the wage subsidy. This suggests that wage subsidies are not effective in changing hiring decisions.

An experiment in the US was conducted to see whether signaling that a gap in employment is due to a chronic health condition leads to a higher callback rate [10]. The authors also sent out three types of fictitious resumes: newly unemployed, unexplained employment gap, and explained employment gap. For the explained gap the cover letter stated that the applicant had to take time off to deal with a medical condition but has since recovered and is able to return to work. In the resume the applicant stated that he or she is a member of a cancer survivor group. Both types of applicants with a gap in employment had, on average, a significantly lower callback rate than the group which was recently unemployed. However, the group with the explained health gap had a significantly higher callback rate than the group with the unexplained gap. This suggests that more job applicants may benefit from explaining the reason for their gap.

\section{Retention of talented workers impacted by chronic health conditions}

Worker turnover can be costly to firms. Firms may thus benefit from trying to prevent chronic health conditions from happening in the first place or by offering flexibility to workers who are impacted. This could especially be the case for those who have accumulated valuable firm-specific skills, as trying to find and train a replacement could be very costly. While preventing chronic health conditions or offering flexibility may be costly in the short term, the long-term gains could outweigh the costs.

A 2016 Danish study examines how bullying in the workplace impacts sickness absenteeism and health outcomes [11]. Instead of directly asking whether workers felt bullied, the authors used the NAQ-R scale, as is common in the workplace bullying literature. Workers are considered to have been bullied if they have experienced at least two negative events on a daily or weekly basis in the last six months. Some examples of negative events include having information withheld that impacts performance, being gossiped about, and being shouted at or the target of angry outbursts. In terms of predicting who was bullied, prior mental health conditions and most work-related characteristics do not matter (the exception being that a longer tenure on the job reduced the likelihood of reporting bullying). However, the workplace-specific effects are large and economically meaningful, suggesting that some work cultures produce much more bullying than others.

Women who were bullied at work were significantly more likely to pick up prescriptions for antidepressants to treat their chronic mental health condition resulting from the bullying. Hence, firms should care about bullying because these women coped by increasing their long-term sickness absenteeism. Men who were bullied reported the same health as women who were bullied, but their strategy for dealing with the bullying was to leave the workforce altogether. Therefore, firms that allow bullying to occur can experience increased levels of chronic mental health conditions among workers, which results in higher levels of costly absenteeism and worker exits. While it is hard to estimate the causal impact of bullying because people who are bullied may be fundamentally different from those who are not bullied, this research shows the importance of workplace culture.

One way that firms have tried to change their workplace environment is to implement workplace wellness programs. One recent study conducted a randomized controlled 
trial in the US to determine if there are any causal benefits to these programs [12]. The authors find that those willing to be randomized into the treatment and control groups had lower spending and healthier habits than those who did not want to participate in the study at all. There was no impact on different types of medical spending, most health care utilization, sick leave, job promotion, job termination, hours worked, and job satisfaction. The only observed impact on medical outcome is that the treated group had more preventative health screenings. The only impact on firm outcome is whether employees thought that management prioritized worker health and safety, but that impact only lasted for one year. These results thus suggest that workplace wellness programs neither prevent chronic health conditions nor improve worker outcomes that firms are likely to care about.

In terms of how firms can retain workers who are impacted by chronic health conditions, partial leave programs have received considerable attention. Given the near unanimous conclusion that partial leave programs promote work among those with chronic health conditions, recent research has focused on the optimal design of such programs [13]. A partial leave program, or grading, creates flexibility by allowing the employee to work at a reduced capacity instead of having to choose between working at the normal capacity or not working at all. However, there are tradeoffs faced when deciding when to resume work and what the capacity trajectory should be. If work resumes too quickly or at too high of a rate, the employee may not be able to make a full recovery, which could be costly to the firm in the long term. On the other hand, if there is too long of a delay or the capacity is set too low, workers may lose valuable skills during that time and never be able to transition back to full-time capacity. A 2019 study examines the optimal policy design of such a program in the Netherlands by using variation across workplace reintegration case managers since these case managers are essentially randomly assigned to workers [13].

The authors find that if the workplace reintegration case manager assigns the work to be resumed within 26 weeks then there is a significant increase in the amount of hours worked by the employee within the next two years, but there is no change in whether the employee returns to work during that time [13]. They also find that starting the initial capacity at a higher rate significantly increases the likelihood of the employee returning to work within the next two years. This suggests that if firms can be flexible in the short term and allow employees to work at a reduced capacity, they can often benefit in the long term by ensuring that the employee recovers enough to resume full-time work. However, there are two important caveats. First, the findings generally apply to physical health conditions, but there is no impact for those with chronic mental health conditions. Second, while partial grading can speed up the recovery, it does not help workers who would not have recovered in the absence of the partial leave program.

Firm flexibility could also be used to retain productive parents when their child is diagnosed with a chronic health condition. In the non-government transfer study from Denmark, the impacts on both parents were largest in magnitude in the year of diagnosis [5]. This suggests that if firms allow parents to shift to part-time work in the short term, many of these retained workers will later be able to return as full-time workers. The research also finds that mothers are marginally more likely to shift to public sector jobs which are known to allow more flexibility in hours worked [5]. This again suggests that firms could keep productive employees in the long term if they are willing to allow for some flexibility in when work is completed. 


\section{LIMITATIONS AND GAPS}

Much of the existing research uses data from Europe and North America. However, chronic health conditions are a global concern, and further work should be done to examine how workers fare in other countries. The variation found within Europe (Figure 1, [3]) suggests that context matters in terms of the labor market outcomes. For example, there is variation in the eligibility rules for and generosity of disability insurance. Therefore, more work could be done on the optimal design of firm policies across countries given these differences.

Research on firm hiring behavior has relied heavily on experiments in which the outcome is the callback rate [8], [9], [10]. However, a callback does not necessarily lead to a job offer, so future research should explore whether there are differences in other stages of the hiring process as well.

\section{SUMMARY AND POLICY ADVICE}

Chronic health conditions often lead to reductions in both wages and employment. Parents and spouses of those with chronic health conditions are also impacted. However, firms could benefit from facing less competition in hiring talented applicants with chronic health conditions. Firms could also benefit from hiring talented workers looking to rejoin the labor force after resolving a health shock compared with hiring workers with unexplained employment gaps.

Research finds that disability wage subsidy programs are not effective at changing firm hiring behavior. In addition, workplace wellness programs have also been shown to be an ineffective way for firms to improve worker health, productivity, or retention. However, reducing bullying can help firms as bullying is associated with increased long-term absenteeism and worker exits. Finally, workplace flexibility can be a way for firms to gain an advantage over their competitors by ensuring they retain their productive employees.

\section{Acknowledgments}

The author thanks an anonymous referee and the IZA World of Labor editors for many helpful suggestions on earlier drafts. Previous work of the author (together with Tine Eriksen, Niels Skipper, and Jannet Svensson) contains a larger number of background references for the material presented here and has been used intensively [5].

\section{Competing interests}

The IZA World of Labor project is committed to the IZA Code of Conduct. The author declares to have observed the principles outlined in the code.

(c) Amanda Gaulke 


\section{REFERENCES}

\section{Further reading}

Neumark, D. "Experimental research on labor market discrimination." Journal of Economic Literature 56:3 (2018): 799-866.

Polachek, S., and K. Tatsiramos (eds). Health and Labor Markets: Volume 47. Bingley: Emerald Publishing, 2019.

\section{Key references}

[1] GBD 2015 Disease and Injury Incidence and Prevalence Collaborators. "Global, regional, and national incidence, prevalence, and years lived with disability for 310 diseases and injuries, 1990-2015: A systematic analysis for the Global Burden of Disease Study 2015." The Lancet 388:10053 (2016): 1545-1602.

[2] Lundborg, P., A. Nilsson, and D.-O. Rooth. "Adolescent health and adult labor market outcomes." Journal of Health Economics 37 (2014): 25-40.

[3] García-Goméz, P. "Institutions, health shocks and labour market outcomes across Europe.” Journal of Health Economics 30:1 (2011): 200-213.

[4] Zhang, X., X. Zhao, and A. Harris. "Chronic diseases and labour force participation in Australia." Journal of Health Economics 28:1 (2009): 91-108.

[5] Eriksen, T., A. Gaulke, N. Skipper, and J. Svensson. The Impact of Childhood Health Shocks on Parental Labor Supply. Aarhus University, Department of Economics and Business Economics Working Paper No. 2020-02, 2020.

[6] Gunnsteinsson, S., and H. Steingrimsdottir. The Long-Term Impact of Children's Disabilities on Families. Copenhagen Business School, Department of Economics Working Paper No. 6, 2019.

[7] Jeon, S.-H., and V. Pohl. "Health and work in the family: Evidence from spouses' cancer diagnoses." Journal of Health Economics 52 (2017): 1-18.

[8] Ameri, M., L. Schur, M. Adya, F. S. Bentley, O. McKay, and D. Kruse. "The disability employment puzzle: A field experiment on employer hiring behavior." ILR Review 71:2 (2018): 329-364.

[9] Baert, S. "Wage subsidies and hiring chances for the disabled: Some causal evidence." European Journal of Health Economics 17:1 (2016): 71-86.

[10] Namingit, S., W. Blankenau and B. Schwab. Sick and Tell: A Field Experiment Analyzing the Effects of an IIIness-Related Employment Gap on the Callback Rate. Working Paper, 2020.

[11] Eriksen, T., A. Hogh, and A. M. Hansen. "Long-term consequences of workplace bullying on sickness absence." Labour Economics 43 (2016): 129-150.

[12] Jones, D., D. Molitor, and J. Reif. "What do workplace wellness programs do? Evidence from the Illinois Workplace Wellness Study.” Quarterly Journal of Economics 134:4 (2019): 1747-1791.

[13] Kools, L., and P. Koning. "Graded return-to-work as a stepping stone to full work resumption." Journal of Health Economics 65 (2019): 189-209.

\section{Online extras}

The full reference list for this article is available from:

https://wol.iza.org/articles/individual-and-family-labor-market-impacts-of-chronic-diseases

View the evidence map for this article:

https://wol.iza.org/articles/individual-and-family-labor-market-impacts-of-chronic-diseases/map 